\section{Mental Disorder and Season of Birth}

Most investigations of the relationship between season of birth and mental illness have found that a disproportionate number of patients with schizophrenia or manic-depression were born in the early months of the year ${ }^{1,2}$. Most of these studies can reasonably be criticized on the grounds that the samples of patients were $(a)$ not representative of all patients, and $(b)$ not comparable with the general population used as the basis of expectation, because seasonal distribution of births in a general population may vary significantly not only from year to year but between adjacent geographical areas in the same year ${ }^{3}$. Dalen's study ${ }^{4}$ largely avoided these criticisms because his schizophrenic patients were representative of the whole of Sweden; he made a decade-by-decade comparison (P. Dalen, personal communication) of years of birth with the general population. He found a very significant excess of the patients had been born in the months January to March.

Here we report further evidence in support of this, using material we believe to be free from these criticisms. Since 1970 , the month as well as year of birth of all persons admitted to psychiatric beds in England and Wales have been recorded, and we used data from all patients first admitted in the years 1970 and 1971 who had been born in England and Wales from 1921. These cases can have no sampling bias and their seasonal distribution of births may properly be compared with the general population of the same geographical area from the year 1921. It was not possible to compare seasonal distributions of month of birth between the two populations before 1939 as it is only from this date that the monthly number of live-births in England and Wales has been published. It was possible, however, to compare seasonal birth distributions in terms of the first, second, third and fourth quarters of the year as these numbers are available for England and Wales from 1921, and the psychiatric admissions in 1970 and 1971 can be regrouped into quarters of the year from the monthly distributions made available to us. The comparisons made by us are therefore undisturbed by any heterogeneities, for example, in variation between urban and rural geographical areas or in variation from year to year, because all these sources of variation are exactly balanced between the two series. The reservations one would have to make to this comprehensive statement are unimportant. The general population cohort born in the year $Y$ will have been reduced due to death and emigration by the year $(Y+x)$ when admissions to hospital occur. Immigration does not enter the picture as persons not born in England and Wales are excluded from the figures. Emigration will have affected the general population cohort by the time in the year $(Y+x)$ when psychiatric morbidity begins to operate, but there is no factual or plausible ground for supposing that emigrants differ in season of birth from the population from which they come. Deaths may, of course, influence the distribution of season of birth in the total population in the years after year $Y$ if, for instance, infants born in one or another season have a higher or lower mortality than others. We consider it exceedingly improbable, however, that there has been any such effect operating on the population as a whole, indifferently of any potentiality to psychiatric morbidity; it can be seen from Table 1 that there is no shift in distribution of season of birth for psychiatric patients as a whole but only for two diagnostic sub-groups, the manicdepressives and the schizophrenics. Only in these two diagnostic groups is a statistically significant shift displayed.

Table 1 shows the observed and expected numbers of births in the first quarter-year for five diagnostic categories. The expected numbers are calculated as follows. If $N_{\mathrm{s}(1921)}$ is the total number of schizophrenic patients born in 1921 and admitted to hospitals in the years 1970 and $1971, B_{1921}$ is the total number of live-births in England and Wales in that year, and $F_{1921}$ is the number of that total born in the first quarter, then the number of schizophrenics, born in 1921, who could be expected to have been born in the first quarter is $N_{\mathrm{s}(1921)} \times F_{1921} / B_{1921}$. All these yearly expectations are summed from year to year to give the total number of expected first-quarter-born schizophrenics for all years up to 1955, so as to provide the schizophrenia total (Table 1). The same procedure was used to calculate the expectations in the other four diagnostic groups. The total expected was then set against the total observed, and one degree of freedom used to estimate the significance of $\chi^{2}$.

Table 1 Observed Numbers of Patients* (by Diagnosis), Born in the First Quarter of the Year Compared with Expectation from all Live Births in England and Wales $\uparrow$

\begin{tabular}{|c|c|c|c|c|c|}
\hline Diagnosis & $\begin{array}{c}\text { Total } \\
\text { patients }\end{array}$ & $\begin{array}{l}\text { Nos. in fi } \\
\text { Observed }\end{array}$ & $\begin{array}{l}\text { st quarter } \\
\text { Expected }\end{array}$ & $\begin{array}{l}\text { Ratio } \\
\mathrm{O} / \mathrm{E}\end{array}$ & $\left(1 \stackrel{\chi^{2}}{\text { d.f. })_{+}^{+}}\right.$ \\
\hline Schizophrenia & 5,139 & 1,383 & $1,292.1$ & 1.07 & 8.55 \\
\hline $\begin{array}{l}\text { psychosis } \\
\text { All other }\end{array}$ & 3,523 & 961 & 883.3 & 1.09 & 9.13 \\
\hline $\begin{array}{l}\text { psychoses } \\
\text { Neurosis }\end{array}$ & $\begin{array}{r}2,852 \\
12,061\end{array}$ & $\begin{array}{r}708 \\
3.056\end{array}$ & $\begin{array}{r}713.9 \\
3.024 .2\end{array}$ & 0.99 & $\begin{array}{l}0.06 \\
0.45\end{array}$ \\
\hline $\begin{array}{l}\text { Personality } \\
\text { disorder }\end{array}$ & 4,479 & 1,114 & $1,127.8$ & 0.99 & 0.23 \\
\hline
\end{tabular}

* All patients born in England and Wales 1921-55 and first admitted to a psychiatric unit 1970 or 1971.

$\uparrow$ Sum of year-by-year comparison.

$\ddagger$ First quarter and the remaining part of the year.

Table 1 shows that for schizophrenia and for manic-depressive psychosis there is a significant excess of births in January to March $(P<0.01)$. The observed numbers in the other diagnostic groups differ only very slightly from expectation. The trend for each diagnosis is the same when the two years of admission are considered separately.

We think these results are important because they add substantially to the evidence for a real association between season of birth and functional psychosis. If real, this is the first association to be demonstrated between the incidence of schizophrenia and a clear-cut, objectively measurable, environmental factor. Moreover, the strength of the association is far from being negligibly small; births in the first quarter exceeded expectation by $7 \%$ for our schizophrenic patients, and by $9 \%$ for our manic-depressives (for the other diagnostic groups, the difference from expectation was about 1\%). There are, of course, many non-causal explanations, the most obvious being a deviance in parental conception habits (in which case the birth pattern of the patients should also be shown by the patients' siblings). Social class differences in season of birth are not likely to be important here, for there is now good evidence that the fathers of patients with schizophrenia and manic-depression do not differ from the general population in their social class distribution ${ }^{5-7}$.

We thank Dr E. R. Bransby and Mr T. Dibley of the Department of Health and Social Security for supplying data.

\section{E. H. HARE \\ J. S. PRICE \\ Eliot Slater}

Bethlem Royal and the Maudsley Hospital, Denmark Hill, London SE5

Received September 13; revised November 21, 1972.

1 Barry, H., and Barry, H., Arch. Gen. Psychiat., 11, 385 (1964)

2 Hare, E. H., and Price, J. S., Brit. J. Psychiat., 115, 533 (1969).

3 Norris, A. S., and Chowning, J. R., Arch. Gen. Psychiat., 7, 206 (1962).

4 Dalen, P., Act. Psychiat. Scand., Suppl., 203, 48 (1968).

5 Hare, E. H., in Recent Developments in Schizophrenia (edit. by Coppen, A., and Walk, A.), Brit. J. Psychiat. Special Pub. No. I (1967).

6 Birtchnell, J., Psychol. Med., 1, 209 (1971).

7 Hare, E. H., Price, J. S., and Slater, E., Brit. J. Psychiat., 121, 515 (1972). 